\title{
IMPACTO DE UMA ABORDAGEM DE DANÇA SOBRE A ANSIEDADE, ESTRESSE E DEPRESSÃO EM UNIVERSITÁRIOS
}

\author{
THE IMPACT OF A DANCE APPROACH ON ANXIETY, STRESS AND DEPRESSION IN COLLEGE \\ STUDENTS
}

https://orcid.org/0000-0003-1309-3173 Josimáteus Geraldo Ataíde Rocha da Silva A https://orcid.org/0000-0001-8701-3266 Evanize Kelli Siviero Romarco ${ }^{B}$

\begin{abstract}
Discente do curso de Dança da Universidade Federal de Viçosa (UFV), Viçosa, MG, Brasil A Docente do curso de Dança da Universidade Federal de Viçosa (UFV), Viçosa, MG, Brasil ${ }^{\text {B }}$

Recebido em: 07052020 | Aceito em: 31052021 Correspondência: Josimáteus (josimateussilva@gmail.com), Evanize (eva.siviero@gmail.com)
\end{abstract}

\section{Resumo}

A ansiedade, o estresse e a depressão são desordens mentais comuns que impactam negativamente a vida dos universitários. Este estudo de campo, de natureza exploratória e descritiva, possui o objetivo de analisar os níveis dessas desordens em participantes de um grupo de vivências corporais baseadas no Contato improvisação (CI). Inicialmente, foi realizado o chamamento público aos estudantes. As práticas foram realizadas duas vezes na semana durante doze semanas, com duração de 60 minutos cada encontro. Foram utilizados quatro questionários: uma ficha sociodemográfica, a PSS, o BAI, e o BDI. Os scores obtidos foram tabulados e analisados. Os dados qualitativos foram registrados a partir de material videográfico e através de um diário de bordo. A abordagem através do CI evidenciou nos voluntários melhoras em aspectos quantitativos e qualitativos sob distintas variáveis que influenciam nessas desordens.

Palavras-chave: Terapia através da Dança; Estresse; Ansiedade; Depressão; Prevenção

\begin{abstract}
Anxiety, stress and depression are common mental illnesses that negatively affect the lives of college students. This field study, exploratory and descriptive in nature, aims to analyze the levels this mental disorders in participants of a bodily experiences group based on contact improvisation (CI). Initially, it was held a public invitation for students. The practices were carried out twice a week during the twelve weeks, lasting 60 minutes at each meeting. Four questionnaires were used: a sociodemographic record, PSS, BAI and BDI. The results obtained were tabulated and analyzed. Qualitative data were recorded from video material and through a logbook. The approach through the CI showed better qualitative and quantitative aspects in the volunteers under different variables that influence these disorders.
\end{abstract}

Keywords: Dance Therapy; Stress; Anxiety; Depression; Disease Prevention 


\section{Introdução}

O estresse, a ansiedade e a depressão são comorbidades mentais, cuja gênese pode ser diversos fatores, dentre eles, causas ambientais frequentemente associadas entre si. Esta pesquisa, com o apoio do PIBIC/CNPq, ocorreu associada a um projeto de extensão universitária intitulado: "Vivências Corporais: Ansiedade, Estresse e Depressão em Universitários", comumente chamado de "Vivências Corporais" ou "Vivências". Nesse projeto de extensão, os autores conduziram os encontros, oportunizaram as vivências e as coletas de dados relacionadas ao impacto do Contato Improvisação (CI) sob essas desordens mentais em estudantes da Universidade Federal de Viçosa.

O ambiente e a própria rotina universitária, por exemplo, são dotados de fatores que podem atuar como agentes estressores e prejudicar a qualidade de vida e o rendimento acadêmico dos estudantes, provocar o abandono do curso ou até mesmo induzir ao suicídio, em casos mais graves, situação não muito incomum em Instituições de Ensino Superior (IES). Logo, o agravo e o aumento considerável do número de estudantes que apresentam indícios dessas disfunções mentais, em sua forma crônica, trazem a necessidade de cuidados à sua saúde mental.

O reconhecimento de tal fato pode ser reafirmado por meio da militância do Diretório Central dos Estudantes (DCE) da Universidade Federal de Viçosa (UFV) no campus de Viçosa, instituição que foi o nosso ambiente de pesquisa, em prol de práticas e políticas que visam à promoção, proteção e recuperação da saúde metal dos universitários do campus.

Embora essa IES, assim como outras universidades, apresente suporte psicológico e de lazer aos universitários, ainda se faz importante estruturar novas estratégias de saúde para a população acadêmica, especialmente nos anos finais e iniciais da graduação e no início no do semestre. Deve-se dar atenção especial à síndrome do estresse e à ansiedade, que culturalmente são ignorados ou vistos com normalidade por seus portadores.

Diversas práticas, tais como atividades físicas regulares, práticas meditativas, yoga, Biodança, terapia cognitiva comportamental (TCC), técnicas de relaxamento e arteterapia são utilizadas como estratégias não farmacológicas visando ao combate e prevenção dessas desordens mentais e seus sintomas. Especificamente para este estudo, abordou-se a dança focando especificamente no Contato Improvisação, que é um estilo improvisacional dançado coletivamente ou em duplas. No presente estudo, o CI é abordado enquanto forma de dança, conforme exposto em Neder (2010) e Faria (2013). Esse estilo foi explorado em sua potencialidade enquanto agente promotor de diálogo, seja ele verbal ou corporal. 
Essa dança, envolve as funções de percepção e adaptação, faculdades que podem estar prejudicadas em quadros de ansiedade, depressão e estresse. Acredita-se que a conectividade criada através dessa modalidade de dança favoreça não somente a comunicação não verbal durante as jam's (nome atribuído aos encontros para a prática do CI (FARIA, 2013)), mas também a comunicação verbal em momentos de dinâmica e de partilha.

Assim, este estudo abordou o CI explorando a poética da oportunidade na dança como recurso facilitador e oportunizador de partilha de vivências, por meio de diálogos, depoimentos e dinâmicas, com o intuito de verificar as possíveis mudanças nos efeitos patológicos que as síndromes de ansiedade, estresse e depressão causam em seus portadores. Logo, teve como objetivo desenvolver um programa de vivências e diálogos em dança mediado pelo CI, com ênfase terapêutica, e o monitoramento das variáveis através de questionários. Esta pesquisa, mesmo com um enfoque terapêutico, também se fez relevante por investigar a dança enquanto área de conhecimento e o Contato Improvisação como uma linguagem artística e seus impactos no controle do estresse, ansiedade e depressão em universitários. Este trabalho contribui com dados acerca dos efeitos da dança na saúde, ampliando a produção científica no assunto. $\mathrm{O}$ estudo também contribui para a validação de outra linguagem da dança, de modo que futuramente possa compor as práticas integrativas complementares do Sistema Único de Saúde (SUS). Essa validação já ocorreu com a Biodança, que é uma modalidade de dança criada por Rolando Toro na década de 1960 e une biologia, psicologia e antropologia para produzir efeitos terapêuticos (BRASIL, 2017a) e, também com a dança circular que é uma prática de dança em roda ancestral, que favorece a conexão entre os participantes e possui enfoque no sentimento de união e pertença e não na técnica (BRASIL, 2017b).

\section{Fundamentação Teórica}

A ansiedade, o estresse e a depressão são males comuns em universitários, tornando-se problemas a serem superados pelas universidades (PADOVANI et al., 2014). A literatura demonstra que a prevalência dessas desordens mentais são mais frequentes nos anos iniciais e finais da graduação, comumente estão ligadas entre si e, também ao maior consumo de álcool e drogas, e são apontadas como causas de baixo rendimento e evasão escolar (DUTRA, 2001; BOLSONI-SILVA; GUERRA, 2014; PADOVANI et al., 2014; LÓPEZ-RODRÍGUEZ et al., 2017). Esses dados são relevantes, uma vez que, cada vez mais, as IES têm buscado apresentar um bom desempenho, no que tange às avaliações de qualidade da instituição (LEMOS, 2011). 
A ansiedade pode ser compreendida como um estado natural do ser humano, cuja definição é difícil, senão, impossível para diversos autores (SANTOS et al., 2017). Contudo, May (1980 apud SANTOS et al., 2017, p. 53) a definiu como sendo "[...] uma relação existente entre a pessoa, o ambiente ameaçador e os processos neurofisiológicos decorrentes desta relação". De modo geral, na literatura, a ansiedade é referida como um estado que prepara o corpo para uma situação ameaçadora (MONTIEL et al., 2014; SANTOS et al., 2017). Inicialmente, é benéfica, pois visa proteger o corpo e a vida, e auxilia no processo produtivo. Por meio dela, o organismo se prepara para a fuga, promovendo alterações cardiovasculares, elevando a pressão arterial e a frequência cardíaca, promovendo a vasoconstrição na pele e nas vísceras e a vasodilatação nos músculos estriados, além da hiperventilação (BLANCO; CANTO-DE-SOUZA, 2018), insônia, taquicardia, palidez, aumento da respiração, tensão muscular, entre outras (SANTOS et al., 2017). Em sua forma crônica ou episódica, provoca alterações fisiológicas e humorais no corpo (AGAPITO, 2009; BRAGA et al., 2010).

O estado patológico acontece quando a sensação de medo ou fuga, cronicamente instalada, traz prejuízos para a vida do indivíduo. Esse evento se dá principalmente quando a sensação de ameaça não é canalizada para um objeto específico (SANTOS et al., 2017). A ansiedade patológica pode acarretar prejuízos na socialização, memória e aquisição de conhecimentos (MONTIEL et al., 2014), o que para um estudante pode ser extremamente prejudicial.

Outra causa de sofrimento psíquico é o estresse, o qual pode ser entendido como um processo complexo gerado por uma resposta não específica do indivíduo a um estressor, que pode ser de origem interna ou externa. A palavra estresse deriva de um termo da física e designa tensão, referindo-se à deformidade sofrida por um material após ter sido submetido a uma tensão ou a um nível de esforço (SILVA, 2015). Esse estado patológico pode ser classificado em: agudo, quando cessa após o contato com o agente estressor, ou crônico, quando se refere ao estado de tensão prolongado com potencial patogênico (SILVA, 2015). Ele também pode ser dividido em três fases, conforme descrito por Pinto et al. (2015):

- Alerta: fase em que o indivíduo ganha energia devido à produção de adrenalina (isso assegura a sobrevivência);

- Resistência: nessa fase o indivíduo tenta lidar de forma automática com os estressores visando à manutenção da homeostasia;

- Exaustão: ocorre dada a persistência dos estressores de modo que há ruptura da fase de resistência. A partir daí iniciam-se as perturbações físicas e psíquicas. 
$\mathrm{Na}$ literatura, observam-se outras classificações para o estresse, como o estresse adaptativo e o estresse de esgotamento mental (SILVA, 2015; GONTIJO et al., 2019). A etiologia do estresse está centrada na capacidade de adaptação e percepções do indivíduo acerca do agente estressor. Neuro fisiologicamente, assemelha-se à neuroquímica da ansiedade (MELLO et al., 2005; SILVA, 2015; BLANCO; CANTO-DE-SOUZA, 2018).

O estresse também produz alterações cognitivas, fisiológicas e de comportamento. Em um contexto normal, torna o indivíduo capaz de lidar com situações adversas, de modo semelhante à ansiedade (AGAPITO, 2009). Em situações patológicas, segundo Pinto et al. (2015) e Silva (2015), o estresse provoca crises de ansiedade, alterações de humor, perda de memória, de concentração, apatia e indiferença emocional. Pode também causar morte neuronal, encurtamento de processos dendríticos, inibição da neurogênese e alterações morfológicas em distintas regiões do cérebro (SILVA, 2015).

Quanto à depressão, é considerada um transtorno psiquiátrico de origem multifatorial, sendo ela o transtorno mais comum. Caracteriza-se pela presença de tristeza, irritabilidade, desprazer, desinteresse, culpa ou baixa autoestima, alterações cognitivas, alterações de sono e apetite, fadiga, pensamentos de morte e fracasso, humor depressivo, perda de interesse e prazer (mínimo de duas semanas), variação de peso corporal e perda de energia, alterações psicomotoras e de sono e redução da concentração (BRANDTNER; BARDAGI, 2009; FORTUNATO, 2012; PINTO et al., 2015). Ela impacta a vida do indivíduo em nível social, funcional e profissional. Alexander Lowen (2017) denota em sua obra que indivíduos depressivos movimentam-se menos que indivíduos saudáveis.

Pessoas acometidas por essa desordem possuem redução das monoaminas, dentre as quais se encontram a serotonina e a dopamina. Há morte neuronal e redução do fator neurotrófico derivado no cérebro $\left(\mathrm{BNDF}^{\mathrm{i}}\right)$, responsável pela diferenciação, plasticidade, resistência e sobrevivência de neurônios. Ela é apontada como fator de morte neuronal no hipocampo, que possivelmente tende a explicar problemas de memória em indivíduos depressivos. Efeito semelhante ocorre na presença do estresse crônico, que afeta a produção do BNDF (PERITO; FORTUNATO, 2012).

Comumente, observa-se a associação entre ansiedade, estresse e depressão. Essas desordens são lesivas à vida produtiva do estudante, influenciando seu rendimento acadêmico, capacidade de tomada de decisões e julgamento, memorização, humor, entre outras (BURATO; CRIPPA; LOUREIRO, 2009; LEÃO et al., 2018). Elas também podem estar associadas ao 
abandono do curso, prejuízos na vida social, Burnout (BRANDTNER; BARDAGI, 2009) e suicídio (BOLSONI-SILVA; GUERRA, 2014; PADOVANI et al., 2014; LEÃO et al., 2018).

Nesse sentido, elementos comuns à vida universitária tornam-se gatilhos para o desenvolvimento dessas desordens mentais, como a adaptação a uma nova forma de avaliação, estabelecimento de novos vínculos, excesso de tarefas acadêmicas, dificuldade para apresentação de trabalhos e aquisição de materiais, cobrança da família acerca de projetos futuros, as incertezas da vida universitária, pressão social e acadêmica, morar com desconhecidos, trabalhar para o próprio sustento, cuidar de si mesmo e de seus pertences, sono insuficiente, entre outras mudanças decorrentes da vida universitária. Devido à mudança de ambiente, o universitário necessita se integrar a uma série de demandas decorrentes dessa nova vida, para as quais deve apresentar recursos cognitivos e emocionais. E, quando presentes, nem sempre essas disfunções são percebidas pelos próprios estudantes (BRANDTNER; BARDAGI, 2009; BOLSONI-SILVA; GUERRA, 2014; PADOVANI et al., 2014; LEÃO et al., 2018).

Como recurso profilático ou de atenuação, a prática regular de atividades físicas é comumente indicada na literatura (GULLICH et al., 2016). Elas auxiliam o corpo na produção de hormônios (em especial, a dopamina e a serotonina), facilitam a interação social e a troca de vivências, e ajudam a regulação do ciclo de sono-vigília. (GULLICH; DURO; CESAR, 2016; ROBLES; VIERA; PÉREZ, 2014). Semelhantes efeitos são observados em outras intervenções não medicamentosas, dentre elas, as práticas somáticas (REGEHR; GLANCY; PITTS, 2013) e as intervenções de dança (FONSECA; VECCHI; GAMA, 2012; LÓPEZ-RODRÍGUEZ et al., 2017; ROBLES; VIERA; PÉREZ, 2014), a qual foi objeto deste estudo.

Lowen (2017), criador da Bioenergética ${ }^{\mathrm{ii}}$, elucida sobre a importância da movimentação corporal, respiração e expressividade para que se possa experienciar a vida. A improvisação em dança, mais precisamente, permite a livre expressão, uma vez que abarca a externalização das experiências coletadas ao longo da vida, que são únicas e experienciadas de modo peculiar por cada indivíduo (HASELBACH, 1988; SILVA, 2009). Na expressividade propiciada por ela, encontra-se seu potencial criativo e artístico, e quando é aplicada para fins terapêuticos, corrobora a concepção de Lowen (2017) sobre o movimento.

Para Haselbach (1988), a improvisação é, primariamente, uma atividade criativa. Enquanto recurso expressivo, trata-se de uma forma não programada e espontânea de expressão e exteriorização das impressões armazenadas em relação ao mundo exterior. Ela surge como uma necessidade humana de transformar o espaço a partir das experiências adquiridas. A transformação mútua e contínua do espaço também é referida por Faria (2013), e definida por 
Martins (2002 apud SILVA, 2009) como um fenômeno decorrente das interações entre o corpo e o ambiente. Sua prática influencia o dançarino em diversos aspectos, como o motor, cognitivo, social, comunicativo, criativo e emocional. De certo modo, observa-se que a improvisação na dança tangencia algumas das propostas e afirmações da Bioenergética, que visa oportunizar ao indivíduo reencontrar-se com seu próprio corpo e explorar ao máximo a vitalidade que há nele (LOWEN, 2017). Outros autores, como López-Rodríguez et al. (2017), também buscaram na dança uma alternativa para a melhora dos níveis de estresse e depressão em universitários.

Por reconhecer as potencialidades terapêuticas e expressivas do movimento, este estudo se dedicou à investigação da dança, enquanto linguagem, dando ênfase ao Contato Improvisação (CI), forma de dança criada em 1972 por Steve Paxton (MOREIRA, 2017).

O CI é um estilo de dança não estilizado, baseado em princípios da física. Ele envolve pontos de contato, peso, fluência, ação e reação. Outra característica importante é o fato de acolher dançarinos de distintos níveis, inclusive, aqueles que desejam começar a dançar. Desse modo, o bom dançarino não é necessariamente o mais virtuoso, mas aquele capaz de dançar e se conectar com o maior número de pessoas. Nesse estilo de dança, os dançarinos se tocam, depositam o peso um sobre outro, reagindo às constantes mudanças (LEITE,2007).

O CI surgiu num contexto de contracultura com o intuito de quebrar as hierarquias e padrões existentes na dança, de modo que qualquer pessoa pudesse praticá-lo (FARIA, 2013; LEITE, 2007; VIDEODA, 2014). Sua difusão se dá através da prática entre os interessados. Logo, não se fundou nenhuma escola ou patente sobre essa linguagem, embora já tenha sido proposto. Contudo, Paxton defendia que tais fatos poderiam limitar o desenvolvimento dessa linguagem de dança, não sendo esse o ideal. Como alternativa, sua parceira, Nanci Stark-Smith, propôs um periódico para viabilizar a troca de informações e orientações (MOREIRA, 2017).

Sendo assim, não existem escolas de Contato Improvisação, tampouco certificação ou formação. Essa se dá na prática entre as pessoas, encontros e leitura de artigos (LEITE, 2007; MACHADO, 2016). Com isso, há o risco imediato de que, embora a transmissão do conhecimento preserve os padrões originais, sejam incorporados a ela percepções e filosofias pessoais, criando incontáveis formas de se transmitir e dialogar nessa linguagem. Para o autor deste estudo, o CI foi apresentado associando seus princípios básicos ao compartilhamento do repertório de movimentos corporais, contudo, ainda mantendo o enfoque sobre as sensações físicas.

Dessa forma, o CI constitui-se em um jogo regido não somente pela inércia e pela gravidade, mas também por sucessões, emergências e oportunizações de poéticas, que se 
transmutam imediatamente ao surgirem em decorrência da imprevisibilidade e da falta de controle sobre o jogo (PADOVAN, 2014). Esse foi o viés escolhido dentro dessa linguagem como proposta de trabalho a ser utilizada neste estudo.

Segundo Faria (2013), o CI pode assumir o caráter de preparação corporal, terapêutico e educação escolar. Nessa modalidade de dança/vivência corporal, para Moreira (2017) e Leite (2007), o contista - nome atribuído a esse tipo de bailarino - necessita reagir, se adaptar e modificar o espaço enquanto recebe inúmeras informações e influências simultaneamente. Desse modo, a estética torna-se sensorial e deve ser sentida, não contemplada.

Em diversos pontos, essa modalidade de dança assemelha-se a uma prática somática, trazendo mais conhecimento do corpo e de si (MACHADO, 2016). Enquanto dança improvisativa, tende a trabalhar com princípios que podem potencializar a expressividade, a sensibilidade, a comunicação, as relações sociais e a capacidade de resoluções de problemas. Além de propiciar o maior autoconhecimento (HASELBACH, 1988; SILVA, 2009; FARIA, 2013), esses fatores podem influir positivamente na saúde e em áreas diretamente afetadas pelo estresse, ansiedade e depressão em universitários (BOLSONI-SILVA; GUERRA, 2014; PINTO et al., 2015; LEÃO et al., 2018), semelhantemente aos efeitos promovidos através da Biodança.

Com isso, este estudo teve por objetivo desenvolver um programa de vivências e diálogos em dança com enfoque terapêutico, através do CI, entre os universitários da UFV e analisar os níveis de estresse, ansiedade e depressão dos participantes.

\section{Metodologia}

Para analisar os efeitos da prática do CI sobre a ansiedade, estresse e depressão foi realizada uma pesquisa de campo de natureza exploratória e descritiva de forma que proporcionasse uma coleta de dados significativa para a sua descrição, reflexão e análise. Foi realizada, também, uma revisão de literatura que incluiu material disponibilizado em sites acadêmicos, na biblioteca da UFV, entre outros, partindo inicialmente da busca pelas seguintes palavras-chave: ansiedade, depressão, estresse, dança, contato improvisação, prevenção, anxiety, depression, stress, dance, contact improvisation, prevention.

A análise quantitativa foi realizada por meio de três escalas descritas no tópico a seguir, e a análise qualitativa, através do registro em material videográfico e de um diário de bordo do pesquisador. Os participantes desta pesquisa assinaram o TCLE, conforme determina a 
Resolução n 466, de 2012, do Conselho Nacional de Saúde. Este estudo foi aprovado pelo comitê de ética da UFV sob o parecer n CAAE 17692719.8.0000.5153.

\section{Procedimentos para a execução da pesquisa}

A pesquisa foi divulgada através de mídias sociais e da comunicação direta com possíveis interessados e possíveis influenciadores, tais como professores, chefes de departamento, e no site da UFV. As divulgações aconteceram de 29/07/2019 a 01/09/2019. Nesse período, também foram fixados cartazes nas mesas dos Restaurantes Universitários (RU's), nos departamentos e laboratórios de graduação e pós-graduação, em locais de grande circulação de universitários.

As inscrições ocorreram no período de 30/07 a 01/09 de 2019, e consistiram no preenchimento de uma série de formulários aplicados pelo pesquisador. Foram incluídos 37 alunos de graduação e da pós-graduação da UFV, no campus de Viçosa, que possuíam idades entre 18 e 35 anos, mínimo de 16 pontos no Índice de Ansiedade de Beck (BAI); 19 pontos no Índice de Depressão de Beck (BDI) e 15 pontos na Escala de Estresse percebido (PSS). Foram excluídos aqueles que atingiram mais que $50 \%$ de faltas ou entregaram os formulários fora do tempo hábil. A amostra final consistiu em 8 universitários.

Foram realizados 24 encontros de uma hora, duas vezes por semana, nos quais foram utilizados desde a facilitação pedagógica progressiva através de roda de conversa à prática do CI e o incentivo a práticas autodidatas, culminando em uma palestra e roda de conversa abertas à comunidade e articuladas pelo grupo.

Os níveis de ansiedade, estresse e depressão foram mensurados em uma pré-avaliação, após seis, e doze semanas através dos seguintes instrumentos:

\section{Inventário de Ansiedade de Beck (BAI)}

O BAI avalia e discrimina os sintomas da ansiedade em 21 pontos, que culminam em uma pontuação que varia de 0 a 63 pontos, classificando o nível de estresse (0-7, ausente ou mínimo; 8-15, leve; 16-25, moderado; 26-63, grave). Ele foi desenvolvido para ser um instrumento confiável capaz de diferenciar a ansiedade da depressão (LACERDA et al., 2017), e foi validado por Cunha (2001 apud BAPTISTA; CARNEIRO, 2011).

\section{Escala de Estresse Percebido (PSS)}


A PSS é dotada de 14 questões estratificadas em 4 qualificações conforme a frequência do evento (nunca a sempre). O somatório final vai de 0 a 56 pontos, sendo a nota final proporcional à gravidade do nível de estresse (LUFT et al., 2007). Visando facilitar a interpretação dos dados, para este estudo, a pontuação foi agrupada e estratificada da seguinte maneira: 0-16 (fraco ou ausente); 17 a 36 (médio); 37 a 44 (grave); 45 a 56 (gravíssimo).

\section{Inventário de Depressão de Beck (BDI)}

O BDI é um instrumento autoaplicável que identifica sintomas de depressão. Foi validado por Gomes-Oliveira et al. (2012). O instrumento conta com 21 questões, variando de 0-63 (0-13, depressão ausente ou mínima; 14-19, leve; 20-28, moderada; 29 a 63, depressão grave).

\section{Análise e Discussão dos Resultados}

A amostra final foi composta por 8 voluntários. A idade média dos participantes foi de 22,25 anos, em sua maioria, graduandos e na primeira graduação (87,5\%), ativos $(75 \%)$, do sexo masculino (100\%), sem algum tipo de acompanhamento psicoterápico $(62,5 \%)$, e $50 \%$ não buscou ajuda durante o semestre, conforme demonstra a Tabela 1, que descreve as variáveis sociodemográficas da amostra.

Tabela 1- Variáveis sociodemográficas e de cuidados com a saúde mental dos voluntários

\begin{tabular}{l|l}
\hline Variáveis & GI n (\%) \\
\hline Idade média (anos) & 22,25 \\
\hline Sexo m & $8(100 \%)$ \\
\hline Sexo f & $0(0 \%)$ \\
\hline Formação superior concluída & $1(12,5 \%)$ \\
\hline Graduandos & $7(87,5 \%)$ \\
\hline Pós-graduandos & $1(12,5 \%)$ \\
\hline Sedentários & $2(25 \%)$ \\
\hline Ativos & $6(75,5 \%)$ \\
\hline Em psicoterapia & $3(37,5 \%)$ \\
\hline Sem acompanhamento psicológico & $5(62,5 \%)$ \\
\hline Não buscou por algum tipo de ajuda durante o semestre & $4(50 \%)$ \\
\hline
\end{tabular}

Fonte: Os autores

Contrariamente à literatura (REZENDE et al., 2008; BRANDTNER; BARDAGI, 2009; CARPENA; MENEZES, 2018), como demonstra a Tabela 1, a procura por cuidados com a saúde mental foi majoritariamente masculina. Os mesmos estudos elucidam que, a população feminina é mais vulnerável às desordens mentais, a população masculina se dispõe menos a 
procurar apoio (BRANDTNER; BARDAGI, 2009). Esse fato também chamou a atenção dos participantes.

Com relação às mudanças sobre o grau de intensidade de ansiedade, estresse e, depressão durante a aplicação das atividades com CI, pode-se observar, pelo Gráfico 1, que o período inicial do semestre foi o mais disfuncional para os estudantes, considerando-se que este possuiu os maiores índices de estresse e depressão. Quanto à ansiedade, ela se manteve em níveis próximos na primeira e na segunda avaliação. Acredita-se que o seu comportamento diferente das demais variáveis se deve ao tamanho diminuto da amostra.

Em contraponto, as três variáveis obtiveram os menores scores com a proximidade do fim do semestre e das férias. Esta redução pode estar relacionada à diminuição da sobrecarga de trabalho acadêmico (em menor volume ou complexidade), à perspectiva de descanso (ao fim do semestre) e, também à participação no Vivências Corporais, considerando os relatos dos participantes sobre a importância do grupo em sua saúde mental. Carpena e Menezes (2018) encontraram resultados semelhantes em seu estudo envolvendo meditação e estresse em universitários. Os autores também atribuem esse fenômeno às nuances das demandas sofridas pelos estudantes.

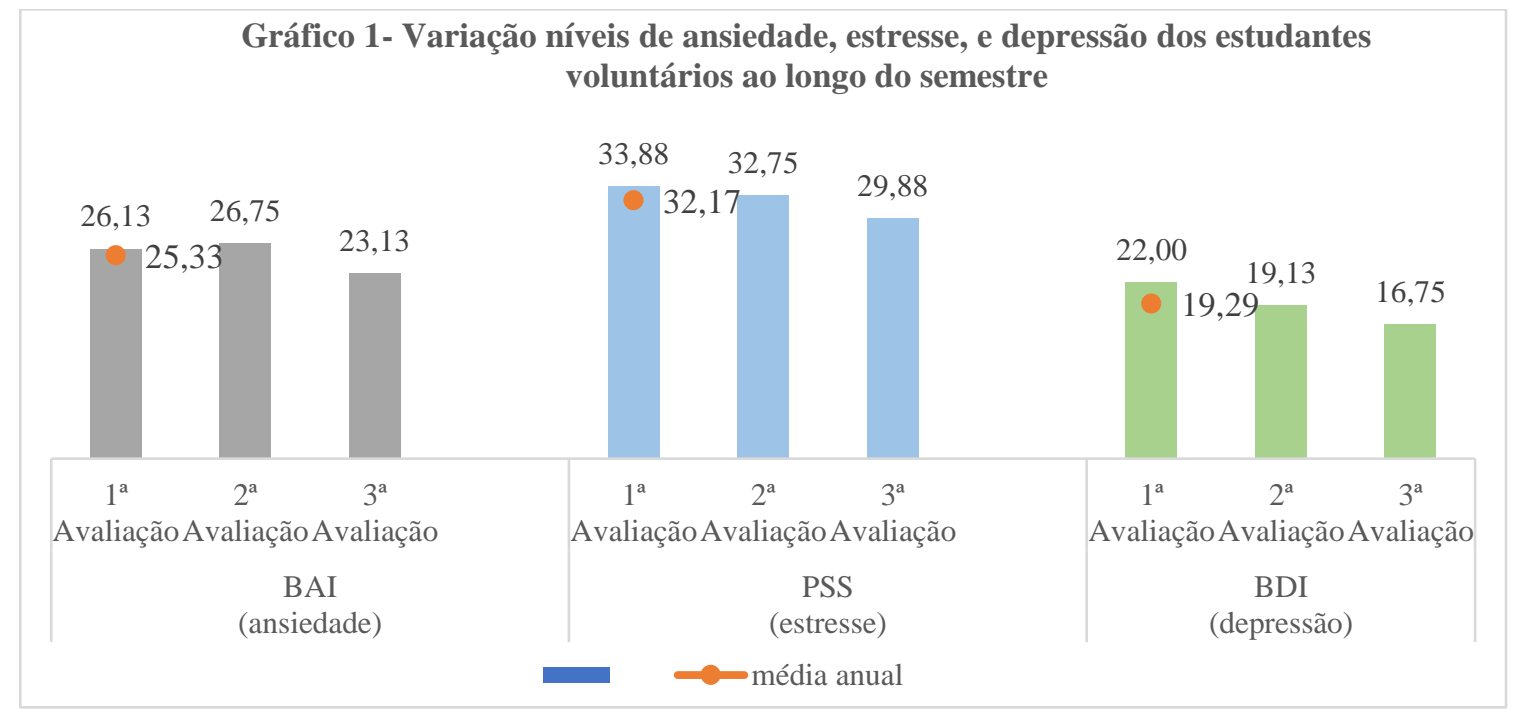

Fonte: Os autores.

O nível médio de ansiedade durante o período avaliado, conforme o Gráfico 1, foi 25,33 e variou entre mediano (16 a 25 pontos) e grave ( 26 a 63 pontos), o estresse, pontuado com a média 32,17, manteve-se qualificado como médio (17 pontos 36). Quanto à depressão, que atingiu a média de 19,29 considerando-se todo o período avaliado, variou de leve (14 a 19) a moderada (20 a 28). 
Não foram encontrados estudos que monitorassem os níveis dessas disfunções ao longo do semestre em universitários para realizar comparação. Contudo, conforme as informações coletadas, acredita-se que a ideação e o retorno ou início da rotina acadêmica sejam os principais fatores geradores dessas desordens. Tal fato pode ser observado na fala do Voluntário 1 (2019), que ao debater sobre os sentimentos negativos que rondavam o Projeto e a Universidade, declarou ter percebido que esse sentimento decorria do fato de os estudantes necessitarem investir muito tempo em coisas indesejadas, o que torna o estudo penoso. Corroborando o Voluntário 1 (2019), Bardagi e Bradtner (2009) e Bolsoni-Silva e Guerra (2014) apontaram a mudança de rotina, o excesso de tarefas, a falta de motivação, as relações pessoais e os novos desafios, como patogênicos aos universitários. E ainda, não se pode ignorar que a necessidade constante de autossacrifícios também pode atuar como fator agravante da situação.

Semelhantemente a Carpena e Menezes (2018), acredita-se que os níveis de ansiedade, estresse e depressão, apresentados no Gráfico 1, sejam proporcionais à produção acadêmica. A provável associação entre a quantidade de atividades exercidas pelo estudante e essas desordens, nesse caso, retroalimentaria um sistema no qual, segundo Schmidt (2013), a demanda de produção e o nível de autonomia do aluno possuem impacto direto na qualidade de sua saúde mental. Estima-se que por ser o período mais longo do semestre, o maior volume de trabalho acadêmico se concentre na parte inicial do período letivo. Infere-se que, nesse momento, os alunos estejam bem e descansados devido ao recesso escolar. Com base nos relatos dos voluntários, observou-se que, com o avançar do semestre, vários participantes sentiram necessidade de reduzir o número de afazeres para aumentar o tempo disponível para se dedicar aos estudos, abrindo mão de sua autonomia (atividades extras) para enfatizar a produção acadêmica. $\mathrm{O}$ abandono de atividades extras para evitar sobrecarga pode ser a causa de evasão desta pesquisa, do Projeto e da redução da frequência dos participantes nas reuniões.

As evasões apresentadas tendem a delinear um padrão ao longo do semestre que aponta não somente a necessidade de se criar mais políticas de saúde mental na UFV, conforme é preconizado na literatura, mas também de oportunizar acesso e permanência a elas. Não foram observados estudos que mencionam fatores de evasão por parte de estudantes nas políticas de cuidado e saúde mental nas IES para que fossem realizadas comparações e a identificação de justificativas. As causas mais frequentes de evasão justificadas foram a dificuldade de tempo para frequentar as reuniões, devido aos afazeres acadêmicos, participação em projetos com 
bolsa, empresas juniores, e afins, no horário estabelecido para os encontros e dificuldade de encontrar tempo para preencher os questionários que, juntos, duravam cerca e 15 minutos.

Embora não tenha sido possível comparar os benefícios da abordagem escolhida de forma quantitativa e comparativa entre dois grupos, observou-se que a intervenção baseada no Contato Improvisação foi importante para a redução dos níveis de estresse, ansiedade e depressão. Tal fato se torna mais evidente a partir da investigação qualitativa, que demonstrou a efetividade da abordagem ao longo do processo nos seguintes aspectos:

Autoconhecimento: A análise qualitativa demonstrou a efetividade da abordagem ao longo do processo nos seguintes aspectos: as vivências assumiram um caráter educativo/somático e permitiram a troca de experiências e saberes de forma orientada, sejam elas mediadas por rodas de conversa, atividades corporais ou dinâmicas e, também por caracterizar-se como um espaço de livre autoexpressão e autoconhecimento.

Para mim, é um dos principais problemas. Até inclusive quando você me fez o convite, eu não me via muito... porque eu não sabia o que estava acontecendo. Se o Projeto [referindo-se ao Vivências Corporais] está sendo importante? Está porquê... não sei... eu sempre achava que sentir ansiedade, estresse... eu sempre tive muito pouca informação acerca da depressão... eu achava que o que eu sentia era normal. Depois que eu entrei aqui, eu percebi que pensar algumas coisas ou sentir algumas coisas não é normal, não deve ser normal, não deve ser naturalizado assim, sabe? Eu acho que isso foi a principal coisa que o Projeto trouxe para mim (VOLUNTÁRIO 1, 2019).

Semelhantemente à fala do Voluntário 1 (2019), Correia e Torrenté (2016), em revisão de literatura, abordando os efeitos da produção artística na reabilitação social de pessoas com distúrbios psicológicos, detectaram diversas mudanças que contribuem para o empoderamento dos pacientes, dentre eles, o convívio social que se atrela à habilidade de gerir e entender a própria doença.

Convívio social: ao conversar sobre a importância do Projeto para cada um e o que notaram de diferente no grupo, as relações criadas foram frequentemente pontuadas.

O Projeto está sendo importante? Sim. Eu acho que sim. Especialmente por causa das ligações sociais que a gente faz aqui no Projeto. Na verdade, eu vou até fazer uma conexão com o que eu notei no grupo ao longo do tempo à importância do projeto... eu vi que as pessoas dentro do grupo começaram a ficar muito próximas umas das outras. E isso é uma coisa muito engraçada e muito peculiar em pessoas que têm dificuldade em se socializar, né?... porque eu não faço amigos, eu não faço amigos fácil. Eu não sou aquela pessoa que 
chega no grupo... começa a falar... faz piada... pega o nome de todo mundo, já decorou o nome de todo mundo [...], porque eu sou ruim de rosto, eu não faço contato visual... eu sou ruim de rosto. [...] Ficamos muito próximos e faz um mês [referindo-se ao grupo]... não, um mês e meio que a gente se conheceu, e eu vejo esses relacionamentos [estalar de dedos em sinal de agilidade]... meio que como você diz, várias pessoas do grupo fazendo amigos [...]. mas é... é isso... é a grande diferença que eu vejo no grupo, sabe? É a galera fazendo amigos, e ficando próxima, e conversando [...] (VOLUNTÁRIO 2, 2019).

Uma coisa que me surpreendeu é que eu não esperava que os laços se aprofundassem tanto. Eu achei que todo mundo ia vir aqui, chegar pra tratar as coisas e pronto. Acabou, ninguém ia começar a conversar com ninguém (VOLUNTÁRIO 3, 2019).

Outros dois participantes relataram que o Vivências era o único lugar onde ficavam felizes em conviver com outras pessoas e também que era o único momento em que dialogavam. A dança, conforme demonstra a literatura, é um importante agente promotor da comunicação e socialização de pessoas com algum problema físico ou mental. A criação de um ambiente não competitivo, no qual as pessoas podem se identificar com o problema alheio, também teve seu papel influenciador no desenvolvimento da sociabilidade e comunicação (CORREIA; TORRENTÉ, 2016; MEJÍA, 2011; VIRIATO et al., 2014).

Autoexpressão: essa variável é notável a partir de elementos sutis, como tomar para si a voz de fala e proposições de temas, a condução autodidata de atividades durante as reuniões, e, também da mudança da qualidade de movimentos, alternando de movimentos contidos e de suporte para movimentos de entrega, de peso e investigação às relações fraternais e empáticas. Houve também uma mudança no padrão de movimentos através de toques, brincadeiras, abraços, entre outras, tal como pode ser observado na fala do Voluntário 3 (2019):

[...] eu era uma pessoa muito fechada para me importar com as outras pessoas, então... não... o que eu notei no grupo é que começou a ter um sentimento muito grande de confiança entre as pessoas, e uma intimidade muito grande também começou a surgir... [...] (VOLUNTÁRIO 3, 2019).

Esse mesmo resultado pode ser visto nos estudos de Mejía (2011), a qual desenvolveu uma abordagem de dança com trabalhadores entre 25 e 50 anos. A autora constatou a redução em $27,7 \%$ da incapacidade de expressar as emoções junto à redução do estresse, e atribuiu a esse evento o efeito de melhora na capacidade de comunicação gerado pela abordagem em dança. Resultados semelhantes foram encontrados por outros estudos (CORREIA; 
TORRENTÉ, 2016; FONSECA; VECCHI; GAMA, 2012; VIRIATO et al., 2014; WITTER et al., 2013).

Outra questão frequentemente pontuada nas reuniões era a importância atribuída ao olhar alheio e à ânsia por atender a essas expectativas, fossem elas reais ou supostas: atitudes e pensamentos condizentes com quem sofre de ansiedade $\mathrm{iii}^{\mathrm{ii}}$. Ao longo do Projeto, foi possível observar uma mudança de atitude em vários voluntários, os quais começaram a priorizar o "sentir-se bem" e, assim, abandonaram estágios por outras atividades de carga horária menor, limitaram o nível de contato com orientador nos momentos de folga, pintaram o cabelo de cor atípica, começaram a abraçar as pessoas de seu convívio, entre outras. Os eventos citados condizem com o aumento da consciência das disfunções, e funcionam como uma forma de autogestão da saúde mental. Todos esses efeitos são atribuídos à arte, de acordo com Correia e Torrenté (2016). Neste estudo, entretanto, é válido ressaltar que alguns dos voluntários realizavam acompanhamento psicológico e psiquiátrico, o que influi no processo.

Positivismo: Voluntário 1 (2019), que passou cerca de quatro semanas sem a possibilidade de frequentar as reuniões, relatou que:

[...] eu acho que o que eu notei no grupo [...] pareciam que algumas pessoas tinham muita dificuldade de falar. [...] hoje eu escutei mais pessoas [...] e uma coisa que eu vi na fala de alguns [...] é que no início a gente falava muito o que "tava" errado. Hoje eu já vi as pessoas falando o que está dando certo. Usando mais coisas positivas que negativas" (VOLUNTÁRIO 1, 2019).

Com o avanço dos encontros, percebeu-se que as colocações reduziram seu caráter expositivo acerca dos problemas e aumentaram as manifestações de ajuda associada à solução e resiliência. Viriato et al. (2014), em sua investigação acerca das contribuições da dançaterapia na saúde mental de pessoas com deficiência física, citam que esse tipo de trabalho favorece a ressignificação existencial da pessoa, permitindo que ela trace metas, faça suas escolhas e planeje seu futuro. Esse potencial da dança, e aqui especificamente o CI, justifica a mudança na fala e no posicionamento de vida dos participantes. De modo semelhante, Correia e Torrenté (2016) identificaram que a arteterapia possui efeito positivo sobre a reconquista da esperança em pessoas com transtornos mentais.

Autoestima, autoconfiança e autonomia: alguns participantes expressavam no início do processo, excesso de sentimento de culpa e incapacidade; apresentavam-se tímidos e melancólicos, sentimentos esses, em boa parte, característicos da ansiedade e da depressão (FARO, 2013; FERNANDES et al., 2018). Embora as características expressadas pelos 
participantes fossem mantidas, observou-se, melhora na postura de empoderamento e redução de queixas. Durante os encontros, os voluntários foram incentivados a trazer, propor e apontar atividades, passando a ter um papel cada vez mais ativo no processo. $\mathrm{O}$ ápice desse processo se deu na elaboração de uma roda de conversa fechada e de uma palestra aberta sobre ansiedade, estresse e depressão. Na ocasião, o grupo decidiu e providenciou o profissional psicólogo.

Autocontrole: o convívio e a troca de informações mediados pela arte vêm se mostrando um importante mecanismo para a troca de vivências e autoconhecimento, gerando empoderamento da pessoa sobre o cuidado com a doença mental. A intervenção baseada na arte também tem demonstrado efeito sobre os aspectos negativos das doenças, dentre elas, emoções negativas (VIRIATO et al., 2014; CORREIA; TORRENTÉ, 2016). Um participante do Vivências, que relatou graves intenções suicidas, obteve melhora no quadro entre a primeira e a última avaliação. Ele relatou que o Projeto era uma forma de buscar um "ponto de saída" ou uma "luz no fím do túnel” (VOLUNTÁRIO 4, 2019). Outros dois participantes relataram melhoras em problemas mais imediatos: Voluntário 5 , desencadeou crises ${ }^{\mathrm{iv}}$ de pânico após ingressar na pós-graduação. Durante uma crise sozinho em casa, o Voluntário 5 experimentou a movimentação trabalhada em sala ${ }^{\mathrm{v}}$ como estratégia de enfrentamento. Constatando a efetividade, ele adotou essa abordagem de dança como rotina de cuidado. Esse participante também tem as crises desencadeadas por exercícios de médio esforço - caminhar rápido, pedalar, etc. - e, ao longo das abordagens no Vivências, se mostrou mais tolerante ao esforço. Semelhantemente, o Voluntário 6, relatou uma crise depressiva em casa. O participante intuitivamente colocou uma música e começou a dançar utilizando a movimentação investigada nos encontros, em seguida, sentiu-se melhor.

A Dança Improvisativa - dentre elas, o CI - permite que emerjam distintas significações ao movimento, denominadas por Silva (2009) como Poéticas da Oportunidade. Enquanto isso, na abordagem terapêutica da Bioenergética, Lowen (2017) elucida que a saúde do corpo está intimamente ligada ao movimento corporal. Quando este se torna limitado em algum grau, surge um fenômeno, denominado couraça, que atua no organismo em nível fisiológico e alimenta-se da energia destinada ao Ego.

As couraças são flexíveis e atuam como um mecanismo de defesa contra experiências ameaçadoras ao corpo (couraças musculares) ou ao Ego (couraças do caráter); elas limitam a capacidade do corpo de amar, sentir e se movimentar enquanto o protege de experiências dolorosas. Alexander Lowen (2017) utilizava-se de dinâmicas corporais e exercícios de movimento, massagens, dentre outras abordagens destinadas ao corpo para promover o 
afrouxamento das couraças a fim de restaurar sua vitalidade e a expressividade, levando-o a um caminho de cura e possibilitando que o indivíduo se abra ao amor.

Por tais fatos expostos, os pesquisadores acreditam que o efeito terapêutico da Dança Improvisativa se encontra no potencial expressivo que o corpo assume (HASELBACH, 1988; SILVA, 2009). Esse potencial pode ser entendido pelo fato de a improvisação ser um fenômeno corporal no qual o corpo, que possui uma história, recebe troca informações com o mundo (SILVA, 2009). Reaver a capacidade de expressão do corpo, está relacionado ao afrouxamento das couraças musculares e egóicas, permitindo que as pessoas se abram à vida e ao amor, conforme afirma Lowen (2017). Logo, a dança, de forma mais específica, o CI, propicia um caminho para a expressão, o amor e a vida. As mudanças de comportamento, as fortes conexões e interações no grupo, poderiam explicar a melhora dos sintomas apresentados e, também estar associadas a esses fenômenos.

Outras literaturas apontam os benefícios terapêuticos da dança são dados em função da adaptação às situações preexistentes, integração e interação social (VIRIATO et al., 2014; WITTER et al., 2013). Os autores apresentam que os efeitos positivos da dança se dão pelo fato de ela propiciar integração social, adaptação às condições preexistentes e à aptidão funcional do indivíduo.

\section{Conclusão}

A abordagem da dança, trabalhada por meio do CI, foi quantitativamente importante para a redução dos níveis de ansiedade, estresse e depressão dos participantes deste estudo. A melhora foi observada também através de aspectos qualitativos de distintas variáveis que influenciam nessas desordens, como: autoconfiança, expressão e controle, positivismo. A abordagem também teve efeito sobre a intenção suicida, episódios de crises depressiva e de pânico entre alguns dos participantes. Houve também mudanças na forma como os participantes passaram a conviver entre si, evidenciando que a dança também possui impacto positivo sobre o domínio social. De fato, a abordagem foi efetiva para a atenuação das disfunções, todavia, quantitativamente, tais dados necessitam de comparação intergrupal com uma amostra homogênea e maior para que se tornem mais evidentes.

Este estudo possui limitações, como a ausência de comparação dos achados com um grupo controle homogêneo. Pelo exposto, sugere-se que novos estudos de abordagem quantiqualitativa sejam realizados com uma amostra maior, visando comparar e esclarecer os impactos de uma intervenção com o CI sobre a ansiedade, estresse e depressão nos estudantes 
da UFV ao longo do semestre. Para tal, acredita-se que os portais Sapiens e o PVAnet, entre outros, possam ser importantes ferramentas de coletas periódicas.

Conclui-se que o CI possui efeito positivo sobre a ansiedade, estresse e depressão. Contudo, novos estudos, com grupo de controle e amostra maior se fazem necessários para uma investigação mais aprofundada.

\section{Referências}

AGAPITO, J. Ação dos exercícios físicos regulares no controle da ansiedade em diferentes populações. Revista Brasileira de Prescrição e Fisiologia do Exercício, São Paulo, v. 3, n. 15, p. 273-283, 2009. Disponível em:

http://www.rbpfex.com.br/index.php/rbpfex/article/view/171.

BAPTISTA, M. N.; CARNEIRO, A. M. Validade da escala de depressão: relação com ansiedade e stress laboral. Estudos de Psicologia, Campinas, v. 28, n. 3, p. 345-352, set. 2011. Disponível em: http://www.scielo.br/scielo.php?script=sci_arttext\&pid=S0103166X2011000300006\&lng=pt\&tlng=pt. Acesso em: 25 mar. 2019.

BLANCO, M. B.; CANTO-DE-SOUZA, A. L. M. DO. Ansiedade, memória e o transtorno de estresse pós-traumático. CES Psicologia, Medellín, v. 11, n. 2, p. 53-65, 2018. Disponível em: http://revistas.ces.edu.co/index.php/psicologia/article/view/4336. Acesso em: 12 set. 2019.

BOLSONI-SILVA, A. T.; GUERRA, B. T. O impacto da depressão para as interações sociais de universitários. Estudos e Pesquisas em Psicologia, Rio de Janeiro, v. 14, n. 2, p. 429-452, 2014. Disponível em: http://pepsic.bvsalud.org/scielo.php?script=sci_arttext\&pid=S180842812014000200004. Acesso em: 6 fev. 2019.

BRAGA, J. E. F. et al. Ansiedade Patológica: bases neurais e avanços na abordagem psicofarmacológica. Revista Brasileira de Ciências da Saúde, [online] v. 14, n. 2, p. 93-100, 2010. Disponível em: https://periodicos.ufpb.br/ojs/index.php/rbcs/article/view/8207. Acesso em: 7 set. 2019.

BRANDTNER, M.; BARDAGI, M. Sintomatologia de Depressão e Ansiedade em Estudantes de uma Universidade Privada do Rio Grande do Sul. Gerais: Revista Interinstitucional de Psicologia. [S.1.], v. 2, n. 2, p. 81-91, 2009. Disponível em:

http://pepsic.bvsalud.org/scielo.php?script=sci_arttext\&pid=S1983-82202009000200004. Acesso em: 6 fev. 2019.

BRASIL. Ministério da Saúde. O SUS das Práticas Integrativas: Biodança. 2017a. Brasília. Disponível em: https://aps.saude.gov.br/noticia/2397. Acesso em: 11 Ago. 2020. 
BRASIL. Ministério da Saúde. O SUS das Práticas Integrativas: Dança Circular. 2017b. Brasília. Disponível em: https://aps.saude.gov.br/noticia/2402. Acesso em: 11 ago. 2020.

BURATO, K. R.D. S.; CRIPPA, J. A. D.S.; LOUREIRO, S.R. Transtorno de ansiedade social e comportamentos de evitação e de segurança: uma revisão sistemática. Estud. psicol. Natal, v. 14, n. 2, p. 167-174, Ago. 2009. Disponível em:

$<$ http://www.scielo.br/scielo.php?script=sci_arttext\&pid=S1413-

CARPENA, M. X.; MENEZES, C. B. Efeito da Meditação Focada no Estresse e Mindfulness Disposicional em Universitários. Psicologia: Teoria e Pesquisa, Brasília, v. 34, n. 1, 2018. Disponível em: https://doi.org/10.1590/0102.3772e3441. Acesso em: 18 Fev 2020.

CORREIA, P. R.; TORRENTÉ, M. DE O. N. DE. Efeitos terapêuticos da produção artística para a reabilitação psicossocial de pessoas com transtornos mentais: uma revisão sistemática da literatura. Cadernos Saúde Coletiva, Rio de Janeiro, v. 24, n. 4, p. 487-495, dez. 2016. Disponível em: http://www.scielo.br/scielo.php?script=sci_arttext\&pid=S1414462X2016000400487\&lng=pt\&tlng=pt. Acesso em: 6 maio 2019.

DUTRA, E. Suicídio de universitários: o vazio existencial de jovens na contemporaneidade. Estudos e Pesquisas em Psicologia, Rio de Janeiro, v. 12, n. 3, p. 924-937, 2001. Disponível em: http://pepsic.bvsalud.org/scielo.php?script=sci_arttext\&pid=S1808-42812012000300013. Acesso em: 23 fev. 2019.

FARIA, Í. R. O Contato Improvisação: bases históricas para um processo de criação. Arte Revista, [online], n. 1, p. 89-106, 2013. Disponível em: http://www.fpa.art.br/ojs/index.php/teste/article/view/28. Acesso em: 3 abr. 2019.

FARO, A. Análise Fatorial Confirmatória das Três Versões da Perceived Stress Scale (PSS): Um Estudo Populacional. Psychology/Psicologia Reflexão e Crítica, Porto Alegre, v. 28, n. 1, p. 21-30, 2013. Disponível em: http://www.scielo.br/pdf/prc/v28n1/0102-7972-prc-28-0100021.pdf. Acesso em: 10 ago. 2019.

FERNANDES, M. A. et al. Prevalência de sintomas ansiosos e depressivos em universitários de uma instituição pública. Revista Brasileira de Enfermagem, Brasília, v. 71, n. supl. 5, p. 2169-2175, 2018. Disponível em: http://www.scielo.br/scielo.php?script=sci_arttext\&pid=S0034$71672018001102169 \& \operatorname{lng}=e n \& n r m=i s o \& t \operatorname{lng}=$ pt. Acesso em: 5 dez. 2019.

FONSECA, C. C.; VECCHI, R. L.; GAMA, E. F. A influência da dança de salão na percepção corporal. Motriz: Revista de Educação Física, Rio Claro, v. 18, n. 1, p. 200-207, mar. 2012. Disponível em: http://www.scielo.br/scielo.php?script=sci_arttext\&pid=S198065742012000100020\&lng=pt\&tlng=pt. Acesso em: 25 mar. 2019. 
FORTUNATO, M. E. S. P. J. J. Marcadores Biológicos da Depressão: Uma Revisão Sobre a Expressão de Fatores Neurotróficos. Revista Neurociências, [online] v. 20, n. 4, p. 597-603, 2012. Disponível em: http://www.revistaneurociencias.com.br/edicoes/2012/RN2004/revisao 20 04/730 revisao.pdf. Acesso em: 7 set. 2019.

GOMES-OLIVEIRA, M. H. et al. Validation of the Brazilian Portuguese Version of the Beck Depression Inventory-II in a community sample. Revista Brasileira de Psiquiatria, São Paulo, v. 34, n. 4, p. 389-394, dez. 2012. Disponível em:

https://linkinghub.elsevier.com/retrieve/pii/S1516444612000487. Acesso em: 13 mar. 2019.

GONTIJO, I. B. R. et al. Validation of the Brazilian Version of the Screening Tool for Psychosocial Distress (Stop-D) for Cardiac Patients. International Journal of Cardiovascular Sciences, Rio de Janeiro, v. 32, n. 5, pág. 438-446, Out 2019. Disponível em: http://www.gnresearch.org/doi/10.5935/2359-4802.20190030. Acesso em: 14 set. 2019.

GULLICH, I.; DURO, S. M. S.; CESAR, J. A. Depressão entre idosos: um estudo de base populacional no Sul do Brasil. Revista Brasileira de Epidemiologia, São Paulo, v. 19, n. 4, p. 691-701, dez. 2016. Disponível em:

http://www.scielo.br/scielo.php?script=sci_arttext\&pid=S1415-

790X2016000400691\&lng=pt\&tlng=pt. Acesso em: 6 fev. 2019.

HASELBACH, B. Dança Improvisação e Movimento: expressão corporal na educação física. Rio de Janeiro: Ao livro técnico, 1988.

LACERDA, M. S. et al. Ansiedade, estresse e depressão de familiares de pacientes com insuficiência cardíaca. Revista da Escola de Enfermagem da USP, São Paulo, v. 51, 2017. Disponível em: http://dx.doi.org/10.1590/S1980-220X2016018903211. Acesso em: 13 mar. 2019.

LEÃO, A. M. et al. Prevalência e Fatores Associados à Depressão e Ansiedade entre Estudantes Universitários da Área da Saúde de um Grande Centro Urbano do Nordeste do Brasil. Revista Brasileira de Educação Médica, Brasília, v. 42, n. 4, p. 55-65, 2018. Disponível em: http://dx.doi.org/10.1590/1981-52712015v42n4RB20180092. Acesso em: 4 dez. 2019.

LEITE, F. H. DE C. Contato improvisação (contact improvisation) um diálogo em dança. Movimento, Porto Alegre, v. 11, n. 2, p. 89-110, 27 dez. 2007. Disponível em: https://seer.ufrgs.br/Movimento/article/view/2870. Acesso em: 5 jan. 2019.

LEMOS, D. Trabalho docente nas universidades federais: Tensões e contradições. Caderno $C R H$, Salvador, v. 24, n. SPECIAL ISSUE.1, p. 103-118, 2011. 
LÓPEZ-RODRÍGUEZ, M. M. et al. Effects of Biodanza on Stress, Depression, and Sleep Quality in University Students. The Journal of Alternative and Complementary Medicine, [online], v. 23, n. 7, p. 558-565, jul. 2017a. Disponível em: http://www.ncbi.nlm.nih.gov/pubmed/28590767. Acesso em: 12 set. 2019.

LOWEN, A. Bioenergética. 12. ed. São Paulo: Summus Editorial.. 2017.

LUFT, C. D. B. et al. Versão brasileira da Escala de Estresse Percebido: tradução e validação para idosos. Revista de Saúde Pública, São Paulo, v. 41, n. 4, p. 606-615, ago. 2007. Disponível em: http://www.scielo.br/scielo.php?script=sci_arttext\&pid=S003489102007000400015\&lng=pt\&tlng=pt. Acesso em: 25 mar. 2019.

MACHADO, M. M. Relações entre Contato Improvisação e as Práticas do BMC. NUPEART, Florianópolis, v. 16, p. 67-79, 2016. Disponível em: http://www.revistas.udesc.br/index.php/nupeart/article/viewFile/8677/6989. Acesso em: 6 maio 2019.

MEJÍA, F. M. Efectos de la danza térapeutica en el control del éstres laboral en adultos entre 25 y 50 años. Hacia la Promoción de la Salud, Manizales, v. 16, n. 1, p. 156, 2011. Disponível em: http://www.scielo.org.co/scielo.php?script=sci_arttext\&pid=S012175772011000100012. Acesso em: 3 jan. 2019.

MELLO, M. T. D. et al. O exercício físico e os aspectos psicobiológicos. Revista Brasileira de Medicina do Esporte, Niterói, v. 11, n. 3, p. 203-207, jun. 2005. Disponível em: http://www.scielo.br/scielo.php?script=sci_arttext\&pid=S151786922005000300010\&lng=pt\&tlng=pt. Acesso em: 6 maio 2019.

MONTIEL, J. M. et al. Caracterização dos sintomas de ansiedade em pacientes com transtorno de pânico. Academia Paulista de Psicologia, São Paulo, v. 34, n. 86, p. 171-185, 2014. Disponível em: http://pepsic.bvsalud.org/scielo.php?script=sci_arttext\&pid=S1415711X2014000100012. Acesso em: 31 ago. 2019.

MOREIRA, B. G. Contato Improvisação como uma Arte de viver [parte 3]. Urdimento, [online], v. 3, n. 30, p. 112-139, 18 dez. 2017. Disponível em: http://www.revistas.udesc.br/index.php/urdimento/article/view/1414573103302017112.

NEDER, F. Steve Paxton entrevistado por Fernando Neder. O Percevejo On-line, Porto Alegre, v. 2, n. 2, 7 abr. 2010. Disponível em: http://www.seer.unirio.br/index.php/opercevejoonline/article/view/1443/1278. Acesso em: 27 mar. 2019.

PADOVAN, L. R. Voar: um mergulho no corpo. O encontro sensível e poético entre dois corpos na dança do contato improvisação e na prática clínica. Dissertação (Mestrado em 
Psicologia) - Universidade de São Paulo, São Paulo, 2014. Disponível em: http://www.teses.usp.br/teses/disponiveis/47/47133/tde-26032015-111601/. Acesso em: 3 jan. 2019.

PADOVANI, R. DA C. et al. Vulnerabilidade e bem-estar psicológicos do estudante universitário. Revista Brasileira de Terapias Cognitivas, Rio de Janeiro, v. 10, n. 1, p. 2-10, 2014. Disponível em: http://pepsic.bvsalud.org/pdf/rbtcc/v10n1/v10n1a02.pdf. Acesso em: 6 fev. 2019.

PINTO, J. et al. Ansiedade, depressão e estresse: um estudo com jovens adultos e adultos portugueses. Psicologia, Saúde \& Doenças, Lisboa, v. 16, n. 2, p. 148-163, set. 2015.

Disponível em: http://sp-ps.pt/downloads/download_jornal/385. Acesso em: 6 maio 2019.

REGEHR, C.; GLANCY, D.; PITTS, A. Interventions to reduce stress in university students: a review and meta-analysis. Journal of affective disorders, [online] v. 148, n. 1, p. 1-11, 15 maio 2013. Disponível em: http://www.ncbi.nlm.nih.gov/pubmed/23246209. Acesso em: 17 mar. 2019.

REZENDE, C.H.A.; ABRÃO, C. B.; COELHO, E. P.; PASSOS, L. B. DA S. Prevalência de sintomas depressivos entre estudantes de medicina da Universidade Federal de Uberlândia. Revista Brasileira de Educação Médica, Rio de Janeiro, v. 32, n. 3, p. 315-323, 2008. Disponível em: http://dx.doi.org/10.1590/S0100-55022008000300006. Acesso em 18 fev 2020.

ROBLES, M. T. A.; VIERA, E. C.; PÉREZ, A. C. O. Los efectos de un programa motor basado en la biodanza en relación con parámetros de inteligencia emocional en mujeres. Cuadernos de Psicología del Deporte, Murcia, v. 14, n. 1, p. 13-21, 2014. Disponível em: http://scielo.isciii.es/scielo.php?script=sci_arttext\&pid=S1578-84232014000100002. Acesso em: 2 jan. 2019.

SANTOS, J. S. et al. A relação da neurofisiologia do transtorno da ansiedade com a neurofisiologia do tabaco. Ciências Biológicas e de Saúde Unit, [online] v. 4, n. 1, p. 51-60, 2017. Disponível em:

https://periodicos.set.edu.br/index.php/fitsbiosaude/article/view/3847/2270. Acesso em 13 fev 2020.

SCHMIDT, D. R. C. Modelo Demanda-Controle e estresse ocupacional entre profissionais de enfermagem: revisão integrativa. Revista Brasileira de Enfermagem, Brasília, v. 66, n. 5, p. 779-788, out. 2013. Disponível em:

http://www.scielo.br/scielo.php?script=sci_arttext\&pid=S0034-

$71672013000500020 \& \operatorname{lng}=$ pt\&tlng=pt. Acesso em: 6 jan. 2019.

SILVA, H. L. DA. Poética da oportunidade: tomada de decisão em estruturas coreográficas 
abertas à improvisação. Salvador: EDUFBA, 2009.

SILVA, E. Efeitos do estresse crônico em áreas do cérebro. Revista Eletrônica da Estácio Recife, [online], v. 1, n. 1, 2015. Disponível em:

https://reer.emnuvens.com.br/reer/article/view/12. Acesso em: 7 set. 2019.

VIDEODA CONTACT IMPROVISATION ARCHIVE COLLECTED EDITION 1972-1983. Direção: Lisa Nelson. Produção: Videoda. Fotografia de Erich Franz: Nancy Stark Smith, Alan Ptashek. Vancouver: [s. n.], 2014. 1 DVD de documentário (2h 15 min), DVD, son., color.

VIRIATO, R. H. et al. Contribuições da dançaterapia no aspecto emocional de pessoas com deficiência física durante programa de reabilitação. Acta Fisiátrica, [online]v. 21, n. 2, p. 6670, 2014. Disponível em: http://www.gnresearch.org/doi/10.5935/0104-7795.20140015.

Acesso em: 6 maio 2019.

WITTER, C. et al. Envelhecimento e dança: análise da produção científica na Biblioteca

Virtual de Saúde. Revista Brasileira de Geriatria e Gerontologia, Rio de Janeiro, v. 16, n. 1, p. 191-199, mar. 2013. Disponível em:

http://www.scielo.br/scielo.php?script=sci_arttext\&pid=S1809-

$98232013000100019 \& \operatorname{lng}=p t \& t \operatorname{lng}=p t$.

\section{NOTAS}

\footnotetext{
' A sigla BNDF é oriunda da língua inglesa: brain-derived neurothophic fator. Ela remete a uma proteína sintetizada pelo corpo que auxilia na diferenciação de neurônios, em sua manutenção, dentre outras funções (PERITO; Fortunato, 2012)

ii Corrente psicoterapêutica corporal, nascida da Orgonoterapia/Vegetoterapia Caráctero-Analítica, de W. Reich, e desenvolvida por Alexander Lowen (LOWEN, 2017, p. 31-39).

iii A ansiedade pode ser entendida como um medo orientado para o futuro de alguma situação real ou imaginária potencialmente lesiva (PINTO et al., 2015). Nesses casos, geralmente esteve associada à aprovação social/familiar. Lowen (2017), aborda a importância do medo da rejeição enquanto fator formador das couraças, um mecanismo de defesa psíquico.

iv $\mathrm{O}$ transtorno de pânico trata-se de um distúrbio de ansiedade (MONTIEL et al., 2014).

${ }^{v}$ Movimentos espontâneos e expressivos, movimentação improvisativa incentivada a partir de bexigas ou outras pessoas, rolamento de livre exploração do espaço, movimentação livre, etc.
} 